\title{
LEVEL OF REPAIR ANALYSIS INCLUDING FAILURE ANALYSIS AND OPTIMAL LOCATION OF MAINTENANCE FACILITIES AND RESOURCES
}

\author{
Eduardo Siqueira Brick ${ }^{1}$, Artur Alves Pessoa ${ }^{2}$ and \\ Karina Thiebaut Sacramento ${ }^{3 *}$
}

Received February 21, 2020 / Accepted October 21, 2020

\begin{abstract}
Level of repair analysis (LORA) aims to determine the optimal repair policy for complex systems' components. A repair policy is an a priori decision about which faulty components to discard or repair, and where these actions should take place. Traditionally, LORA models have assumed the maintenance network as pre-defined and identified the resources required to perform the maintenance at each facility as an output. In this paper, the maintenance network itself is an output rather than an input. Other advantages are the ability to deploy different types of resources at the operational level and to allow precise identification of the faulty component. We propose a mixed integer programming (MIP) formulation for the optimization problem, associated with a flow model. Experiments using a set of hypotheticals, but adequate for the purposes of the study, instances provide strong evidence that the formulation's capabilities can lead to significant cost savings.
\end{abstract}

Keywords: maintenance, level of repair analysis, mixed integer programming.

\section{INTRODUCTION}

Organizations engaged in manufacturing goods or providing services often rely on large quantities of capital assets (systems, equipment, machinery, tools, etc.) subjected to frequent failures or functional losses. Problems caused by faulty components often interrupt productive activities. Consequently, it is necessary to restore the production capability. Sometimes it is cost effective

\footnotetext{
*Corresponding author

${ }^{1}$ Universidade Federal Fluminense (UFF), Departamento de Engenharia de Produção (TEP), Rua Passo da Pátria, 156, sala 306, Bloco D, S. Domingos, Niterói, RJ, Brazil - E-mail: brick@ producao.uff.br - http://orcid.org/0000-0002-62483680

${ }^{2}$ Universidade Federal Fluminense (UFF), Departamento de Engenharia de Produção (TEP), Rua Passo da Pátria, 156, sala 306, Bloco D, S. Domingos, Niterói, RJ, Brazil - E-mail: artur@ producao.uff.br - http://orcid.org/0000-0002-74214744

${ }^{3}$ Universidade Federal Fluminense (UFF), Departamento de Engenharia de Produção (TEP), Rua Passo da Pátria, 156, sala 306, Bloco D, S. Domingos, Niterói, RJ, Brazil - E-mail: karinathiebaut@ gmail.com - http://orcid.org/0000-0003$2358-8225$
} 
to repair the product upon failure, instead of buying a new one, and customers increasingly take total life cycle costs (LCC) into account in their purchasing decisions. Many sectors face this situation: transportation (Saranga \& Kumar, 2006), manufacturing, energy, defense (Cassady et al., 2001), communications and information technology, among others.

Capital asset's components usually present a tree-like structure with several indenture levels. The lowest level in Fig. 1 (Ind.0) represents the asset itself, whereas the highest (Ind. 3) represents the simplest and indivisible components (bolts, nuts, transistors, coils, etc.). There are different criteria adopted to perform system breakdown. The most often used one considers the capability of a particular operational unit to identify and extract a faulty part from its parent and replace it with a good one. This capability is a function of the resources deployed at the site. A Line Replaceable Unit (LRU) is a part replaced using resources normally available at the operation site where the asset is located, whereas a Shop Replaceable Unit (SRU) is one that requires specialized facilities, skills and tools to perform this action. Therefore, whether one considers a component to be a LRU or a SRU depends on which resources are available at an operational unit. In this paper we assumed that these resources are also subjected to decision choices and, for that reason, it was necessary to define a new type of component: a Shop or Line Replaceable Unit (SLRU), one that can be either a LRU or a SRU, depending on the maintenance resources deployed. Fig 1 exemplifies a partial system breakdown using this representation.

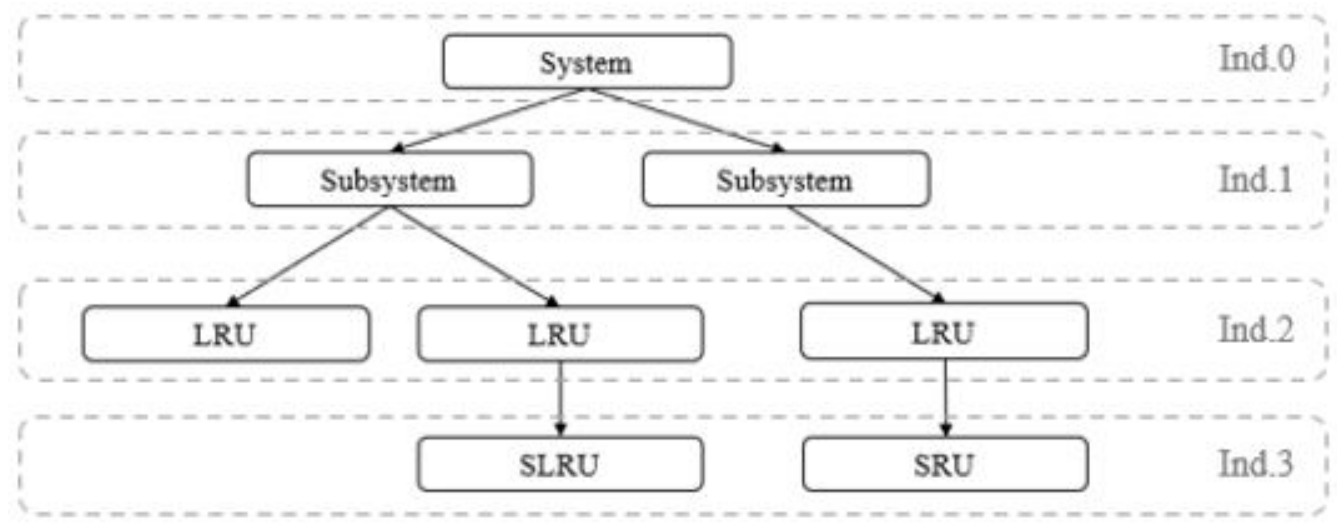

Figure 1 - Example of a system tree structure.

This compartmentalized view of the capital assets naturally induces a hierarchical structure for the maintenance network itself. The structure adopted by the United States Department of Defense (DoD) has four levels, as illustrated in Fig. 2.

The lowest echelon, also referred to as operation site, contains the productive assets. The second and third echelons, called intermediate workshop and depot respectively, carry different maintenance actions, and the fourth echelon normally refers to the facilities of the original equipment's (or component's) manufacturer (OEM). Echelons are associated with different capabilities to execute maintenance actions. The operation sites can only perform simple actions, such as exchange 
of LRUs. The highest echelons can perform complex actions, which require more effective and higher cost repair resources.

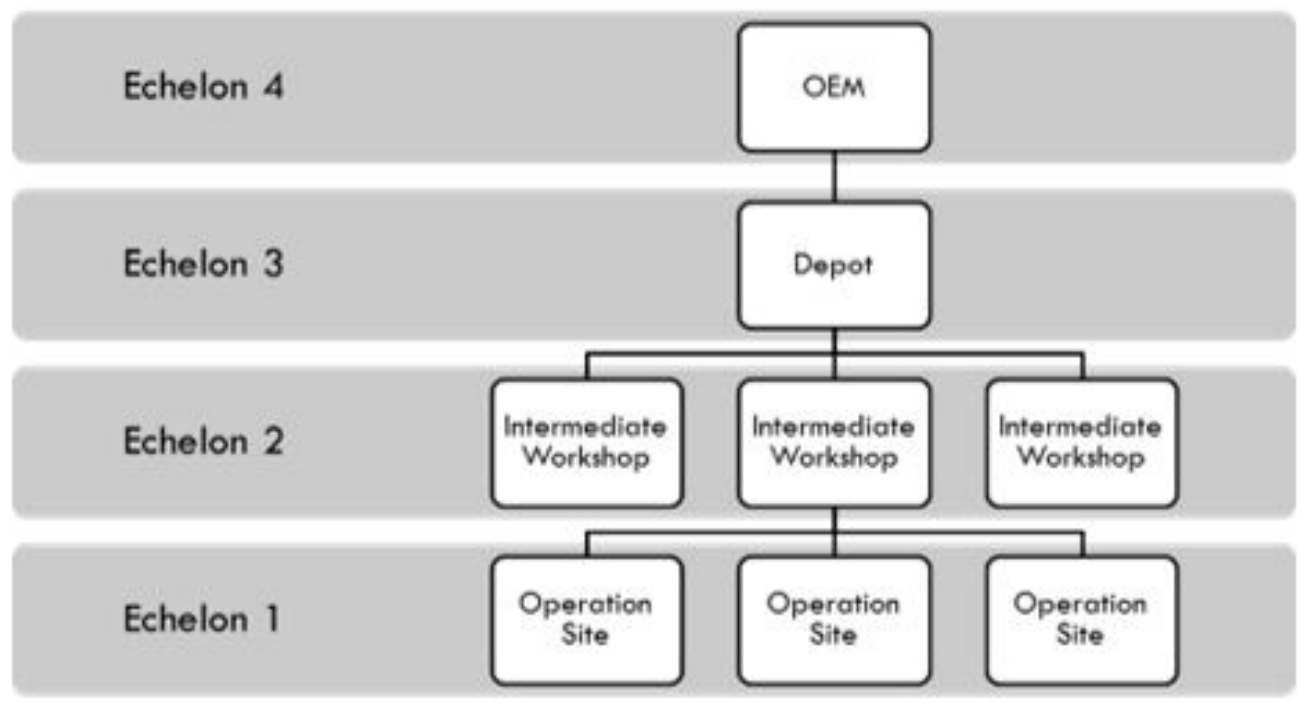

Figure 2 - Example of maintenance structure with four echelons.

Military departments worldwide use a variety of methods to address logistics support system design, known as logistics support analysis (LSA) tools. One of them is level of repair analysis (LORA). According to the DoD (United States Department of Defense, 1993) LORA's purpose is "to establish the least-cost feasible repair level or discard alternative for performing maintenance actions and to influence equipment design in that direction. The analyses are based on economic and noneconomic considerations and readiness objectives."

According to Basten, Schutten \& van der Heijden (2009), "Given a product design and a repair network, a level of repair analysis (LORA) determines for each component in the product (1) whether it should be discarded or repaired upon failure and (2) at which echelon in the repair network to do this. The objective of the LORA is to minimize the total (variable and fixed) costs."

A more general LORA problem may include the following decisions:

1. Which components to consider as LRUs or SRUs;

2. Where to locate maintenance facilities;

3. What resources to deploy at each maintenance facility;

4. How to organize the maintenance network (what echelon structure to adopt); and

5. Which alternative components to choose when designing the system. 
A single problem involving all these decisions would be far from being tractable for the current state-of-the-art techniques. This paper aims at moving toward this goal.

\subsection{Literature Review}

Alfredsson (1997) was the first to propose optimization models to solve LORA problems. He considered LORA jointly with the spare parts inventory problem, assuming many simplifications: one system, with only one product indentation level, and all components being LRUs. Another assumption was that the repair of each component required only one test device. The author considered fixed and predefined support structure, with three echelons, and that repairs requiring identical test equipment can only occur at the same echelon level. The objective was to maximize a measure of the system's availability, subject to a limit on life cycle cost.

Basten, Schutten \& van der Heijden (2009) proposed a mixed integer programming (MIP) formulation for the problem of deciding which among three actions (discard, repair or move to the next echelon) to perform in a fixed multi-echelon maintenance network, considering the variable and fixed costs of resources employed in these actions. For the more general problem, where the model must also decide where to perform each action, the authors showed that it is NP-hard. We remark that since the model proposed in this paper includes the one proposed by Basten, Schutten \& van der Heijden (2009) as a particular case, the resulting optimization problem is also NP-hard.

Lins and Droguett (2009) studied the impact of the redundancy's allocations in maintenance systems reliability and costs by using a multi objective genetic algorithm coupled with discrete event simulation.

Cassady, Murdock \& Pohl (2001) and Basten, van der Heijden \& Schutten (2011a) considered that repair actions may be unsuccessful and require rework. Basten, van der Heijden \& Schutten (2011a and 2011b) solved the problem by using a minimum cost flow model that allows for moving the component to another echelon in addition to repairing and discarding it. In this work, we also consider unsuccessful repair attempts and, further, use the probability of failure of repair attempts combined with repair action and maintenance resource costs to determine the most suitable multi-echelon maintenance structure for each possible failure mode.

Basten, van der Heijden \& Schutten (2012), Fan et al. (2013), Guo et al. (2015), Ghaddar, Sakr \& Asiedu (2016), Rawat \& Lad (2015), following Alfredsson (1997), also addressed the availability problem, and presented algorithms to find optimal solutions for the joint problem of LORA and spare part stocking. To our knowledge, these are the only papers that have considered spare part stocking and system availability in LORA problems.

Barros (1998) and Barros \& Riley (2001) assumed that all components in each indentation level could share the same maintenance resource. Cassady, Murdock \& Pohl (2001) and Scheneider \& Cassady (2015) discussed the selective maintenance problem, where available resources may not be sufficient to perform all maintenance actions demanded, making it necessary to choose the 
best within a set of maintenance actions (repair, substitute faulty components or even functioning parts preventively).

Saranga \& Kumar (2006) assumed three echelons, three product indentation levels, and that fixed costs (of facilities, test equipment, human resources, software, etc.) are a step function of demand. They proposed a mathematical programming formulation, solved with genetic algorithms. The formulation requires previous evaluation of the portion of the fixed cost associated with each maintenance action. Buachera, Kishk \& Power (2010) also addressed the LORA problem using genetic algorithms with tabu search.

Brick \& Uchoa (2009) generalized the definition of the LORA problem by extending it to include a fourth decision regarding where to locate maintenance facilities, based on geographical coordinates. Previous papers considered the maintenance network as pre-defined. To our knowledge, this is the only paper so far examining repair policy decisions simultaneously with facility location ones. The authors chose not to classify the repair facilities by echelons. The operating site, which only performs LRU replacements, and an additional maintenance echelon form a two-echelon network. Which facilities should be opened and where is a part of the decision problem. The model accepts capacitated resources, assumes that different components can share the same maintenance resources and there is no limit as to the number of resources at a given site. The fixed cost of resources, as well as the variable cost for maintenance actions, may depend on the location. Transportation costs depend on component parameters (cost, weight, volume, etc.), transportation modes, distances between locations, and even origin and destination.

Shiina et al (2017) also proposed a method for identifying the optimal facility location installation and capacity with the minimum installation cost.

Parada Puig \& Basten (2015) addressed a problem closely related to the LORA problem: the identification of components treatable as LRUs (the remaining components are SRUs). This problem occurs in multi-component maintenance optimization methods. One of the concerns is the structural dependence among components, which may affect their replacement. They considered the LRU definition problem as deciding which item to replace locally on the occurrence of each type of failure. A maintenance system services a fleet of assets, and the acquisition of standby assets compensates unavailability due to maintenance downtime. The objective of their LRU-definition problem is to minimize the total cost of item replacement and the investment in additional assets, given a constraint on the availability of the fleet of assets. The maintenance network is fixed and has only two echelons. The model proposed in this paper also considers a LRU definition problem and introduces the acronym SLRU (Shop or Line Replaced Unit) to denote a component for which the decision on classification as SRU or LRU is a model output.

More recently, Rawat \& Lad (2016) used the LORA method to support decisions concerning optimization of system component reliability. Rawat \& $\operatorname{Lad}(2017,2018)$ also considered time-dependent failure rates and addressed the joint optimization of level of repair (LOR) and preventive maintenance scheduling. Rawat et al (2020a) and Rawat \& Lad (2020b) used joint optimization for reliability design (RD) and level of repair analysis (LORA) for fleet systems. 


\subsection{Contributions}

This work proposes a new model that encompasses the first four decisions mentioned in the first part of this section, and indirectly also the fifth one. It presents a MIP formulation for the underlying optimization problem. The proposed model considers a wider range of possible alternative actions, by adding the following modelling capabilities not previously considered:

- Two levels (high and low) for resource effectiveness and capacity;

- Possibility to deploy resources at the operating level, creating the ability to precisely identify the fault mode and replace the component that caused the system's failure; and

- Allowance of customized multi-echelon structures for the maintenance network, depending on demand type and origin.

Note that the second feature may lead to lower costs by avoiding sending more expensive, voluminous and/or heavier parent parts for discard or repair, instead of only the faulty child. This amounts to solving, simultaneously with the traditional LORA decision, the LRU definition problem introduced by Parada Puig \& Basten (2015).

Moreover, the third feature makes a relevant and innovative contribution, since the maintenance structure, including its organization into echelons, is an output, based solely on geographical distribution of demand and maintenance resource characteristics, rather than an input. The only previous work including this feature assumed a fixed two-echelon structure (Brick \& Uchoa, 2009).

To test the proposed model, we use a set of realistic, albeit hypothetical, benchmark instances. Those instances are based on a toy system, real Brazilian geographical data, random failure rates and fixed and variable costs. The benchmark set allowed to evaluate potential cost reductions provided by each model feature independently. The test instances also attested the model ability to generate complex maintenance structures, with up to four echelons. Therefore, they were adequate for the purpose on hand, which was to compare the effects of the various model features.

The remainder of this paper is organized as follows. Section 2 presents the formal description of the problem. In Section 3, we introduce an alternative representation of this problem as a network flow problem. Based on this representation, we propose a MIP formulation to solve the problem in Section 4. Section 5 contains a description of the experimental environment as well as the corresponding results. Finally, Section 6 provides our conclusions and comments.

\section{PROBLEM DESCRIPTION}

Consider operation sites at different geographical locations belonging to a set $K$, deploying various kinds and quantities of productive assets. Maintenance sites are possible in a set $J$ of possible geographical locations, which includes set $K$ as a subset $(K \subseteq J)$, as shown in Fig. 3 . 


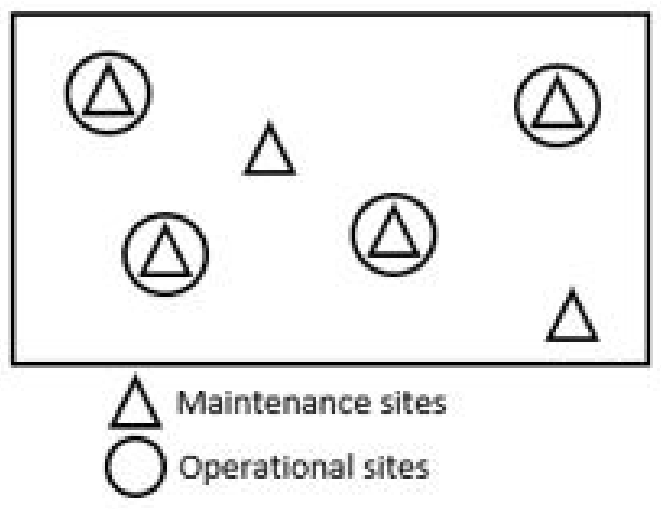

Figure 3 - Subsets of operational and maintenance sites.

It is important to introduce the definition of a built-in test equipment (BITE) at this point. A BITE is an equipment able to identify the fault that caused the failure, or at least one component in the tree structure that contains the faulty part (e.g., see Pecht et al., 2001; Drees \& Young, 2004; Previsich, 2007; Ungar, 2010). Often, BITE can identify faulty LRUs.

When an asset fails, the start of the maintenance process depends on some fault indication of a component, a precondition for its substitution. The supported assets consist of subsets of the component set Q. Each component may fail according to one or more fault modes (also referred as precise fault indications), belonging to the set $T_{2}$.

There are two possible fault indications: a BITE indication, represented by $t^{\prime} \varepsilon T_{1}$, which may be imprecise; and a clean-cut indication, represented by $t$ " $\varepsilon T_{2}$. We consider that a BITE indication $t$ ' has to undergo a pre-analysis to generate a precise fault indication $t$ '. In our model, BITE indications can only refer to LRU at the first indenture level of the assets (represented as subsystems in the example in Fig 4). Sets $T_{1}$ and $T_{2}$ compose the set $T$ of all possible fault indications. Each fault indication (BITE or precise) $t \varepsilon T$ is associated with a faulty component $q \in Q$, as shown in Fig. 4. As we consider pre-analysis as $100 \%$ effective, it can point the exact fault and the LRU, SRU or SLRU where it is located. Fig. 4 below presents an example of components and possible fault indications. In this figure, there are two possible BITE indications $\left(t^{\prime}=1,2\right)$ and five precise fault indications, each one univocally associated with a fault mode ( $t$ ” $=3,4,5,6$, and 7 ). If pre-analysis in LRU 2 points to fault 5 or 6 , the faulty component is LRU 2 itself. In the other hand, if it points to fault 7, the failure occurred in SLRU 1. For this example, let's suppose that the replacement of SLRU 1 requires resource A, which is not available at the operational site. In this case, SLRU 1 has to be considered as a SRU. If resource A is available at the operational site, SLRU 1 can be replaced and, by definition it's a LRU.

It's usual aircraft avionic subsystem to have only one component, in this case a LRU. The operational site can replace it when a failure occurs. This is the situation represented by subsystems I and 2 in Fig 4.We also assume that original demands, which are the starting point for all main- 


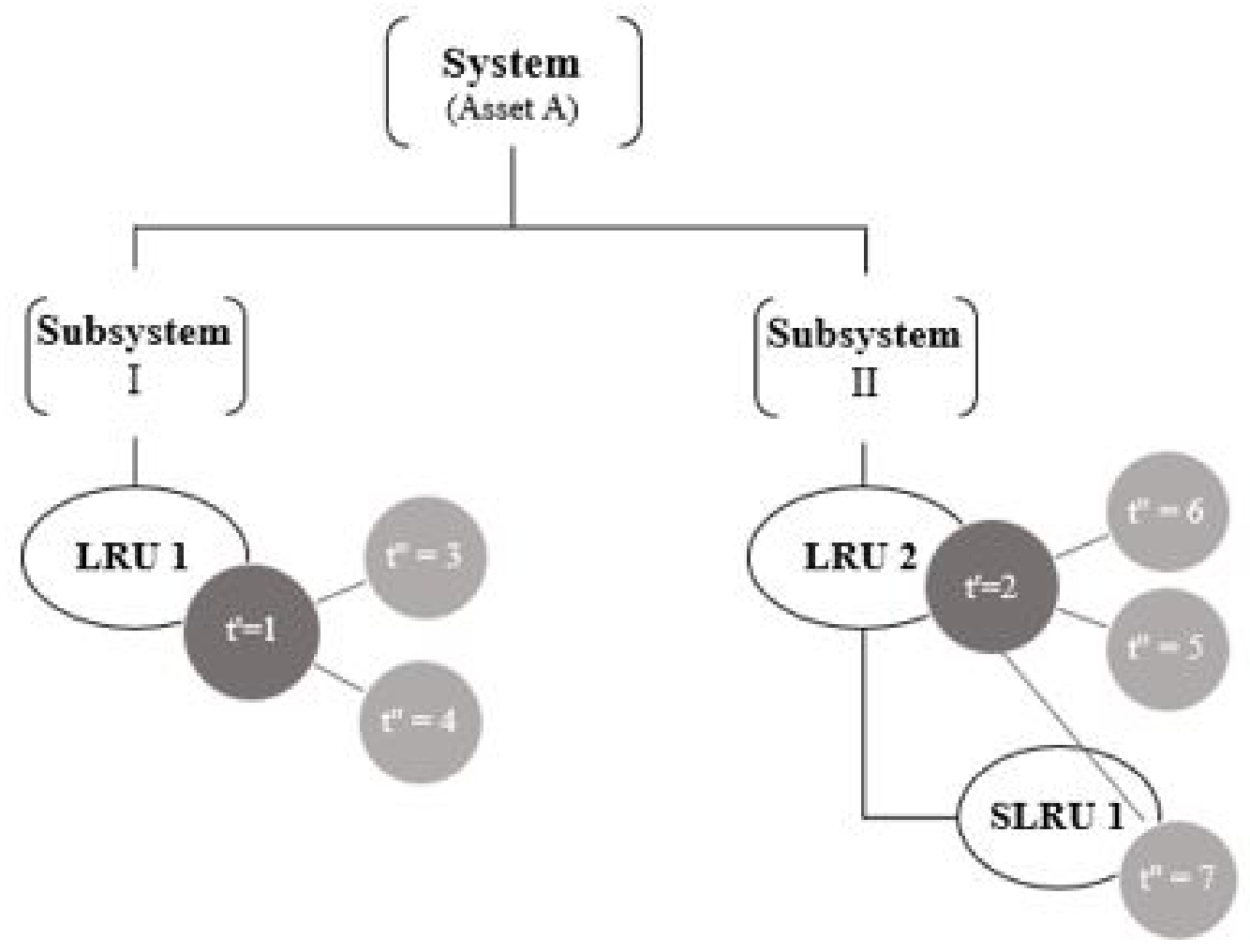

Figure 4 - Example of an asset tree structure and fault indications.

tenance actions, always derive from BITE indications generated at operation sites. Thus, in case of repair, pre-analysis is always required to identify precisely the fault and the component where it is located. Another option is to discard the component and replace by a new one. Precise fault indications allow discarding or repairing the associated components. Both operation and maintenance sites can originate requests for pre-analysis and repair. If the pre-analysis occurs at an operation site, we assume that it is also possible to remove the identified component to perform a maintenance action, and the component becomes a LRU.

Each fault indication $t$ triggers a specific maintenance action $a$, chosen from a set $A$ of feasible ones, depending on the location where the fault occurred.

The proposed model also allows the use of many sets of resources to perform the maintenance action with different effectiveness. Nevertheless, for simplifying reasons, in this study, we allow only two resource sets to perform the same maintenance action: a resource set with lower effectiveness and lower cost (referred to as Resource Set 1), and another one with a higher effectiveness and cost (referred to as Resource Set 2). This simplification aims to reduce the problem's size (reducing nodes and echelons) and to allow a solution in a reasonable time. However, the model can be used with any value of effectiveness. 
Resource sets that are more effective result in less rework, and may lower the total cost. Therefore, one of the possible LORA decisions with relevant cost implications is which resource set to choose.

The following maintenance actions $a \in A$ are possible:

$(a=1)$ Analysis (Pre-analysis);

$(\boldsymbol{a}=2)$ Disposal (Discard);

$(\boldsymbol{a}=\mathbf{3}, \mathbf{5}, \mathbf{7}, \ldots)$ Repair with Resource Set 1 (first, second, third, ... attempt, respectively);

$(\boldsymbol{a}=\mathbf{4}, \mathbf{6}, \mathbf{8}, \ldots)$ Repair with Resource Set 2 (first, second, third, ... attempt, respectively);

Each maintenance action $a \in A$ uses a specific subset of the resource type set $R$. Table 1 below shows an example:

Table 1 - Resources for maintenance actions.

\begin{tabular}{|c|c|}
\hline Maintenance action $(\operatorname{set} A)$ & Resource $($ set $R$ ) \\
\hline Analysis & Worker and pre-analysis and replacement kit \\
\hline Disposal & Worker \\
\hline Repair & Equipment and worker \\
\hline
\end{tabular}

In case of disposal, a new component is acquired. This maintenance cycle ends when the repaired component, or a new one in case of discard, returns to the operation site.

For each $t^{\prime} \varepsilon T_{1}$ and $k \in K$, the parameter $d_{t^{\prime} k}$ denotes the demand for $t^{\prime}$ in site $k$ (number of BITE indications of type $t^{\prime}$ occurring at operation site $k$ ). Moreover, for each $t^{\prime} \varepsilon T_{1}$ and $t^{\prime \prime} \varepsilon T_{2}$, the parameter $\gamma_{t^{\prime}} t^{\prime}$ represents the probability that the BITE indication $t^{\prime}$ is a consequence of fault $t$ ", identified after pre-analysis. Component failure rates are the sum of the failure rates $\left(\lambda_{t}{ }^{\prime \prime}\right)$ of the associated fault modes $t$ ". The total demand on a location $k$ depends on both the component failure rate $\lambda_{q}$, and the number of assets deployed at location $k$.

It is possible the occurrence of unsuccessful repair actions, requiring a new maintenance attempt, possibly with more effective (and expensive) resources. We use the following assumptions:

1. The success probability of each possible maintenance action for each fault indication $\left(\alpha_{t a}\right)$ is known;

2. Up to $N$ attempts on the same faulty component can be performed;

3. It is possible to perform two consecutive repair attempts (one rework) at the same site, but only using a more effective and costly resource set than the one previously used. On the other hand, if the previous attempt took place at another site, any resource set may be used;

4. The last ( $N$ th) repair attempt requires the use of a $100 \%$ effective resource set, deployed at any site. If the most effective resource set is not $100 \%$ effective, the only option left in the $N$ th attempt is to discard the item. 
Since the model assumes that it is possible for a maintenance action to fail, the following allowed actions depend on previous ones. Therefore, it is necessary to keep track of what happened to each component since it entered the network. This information is represented by the repair attempt index $i \in I$, which qualifies the type of maintenance demand arriving at a site as a function of previous repair attempts. The repair attempt indices used are:

$(i=1)$ the component has not yet been analyzed;

$(i=2)$ the component was analyzed and has not undergone any repair;

$(i>2)$ the component has undergone $(i-2)$ repair attempts.

Fig. 5 exemplifies how maintenance actions connect to repair attempts, assuming $N=3$ and that repairing with Resource Set 2 is $100 \%$ effective (but Resource Set 1 is not):

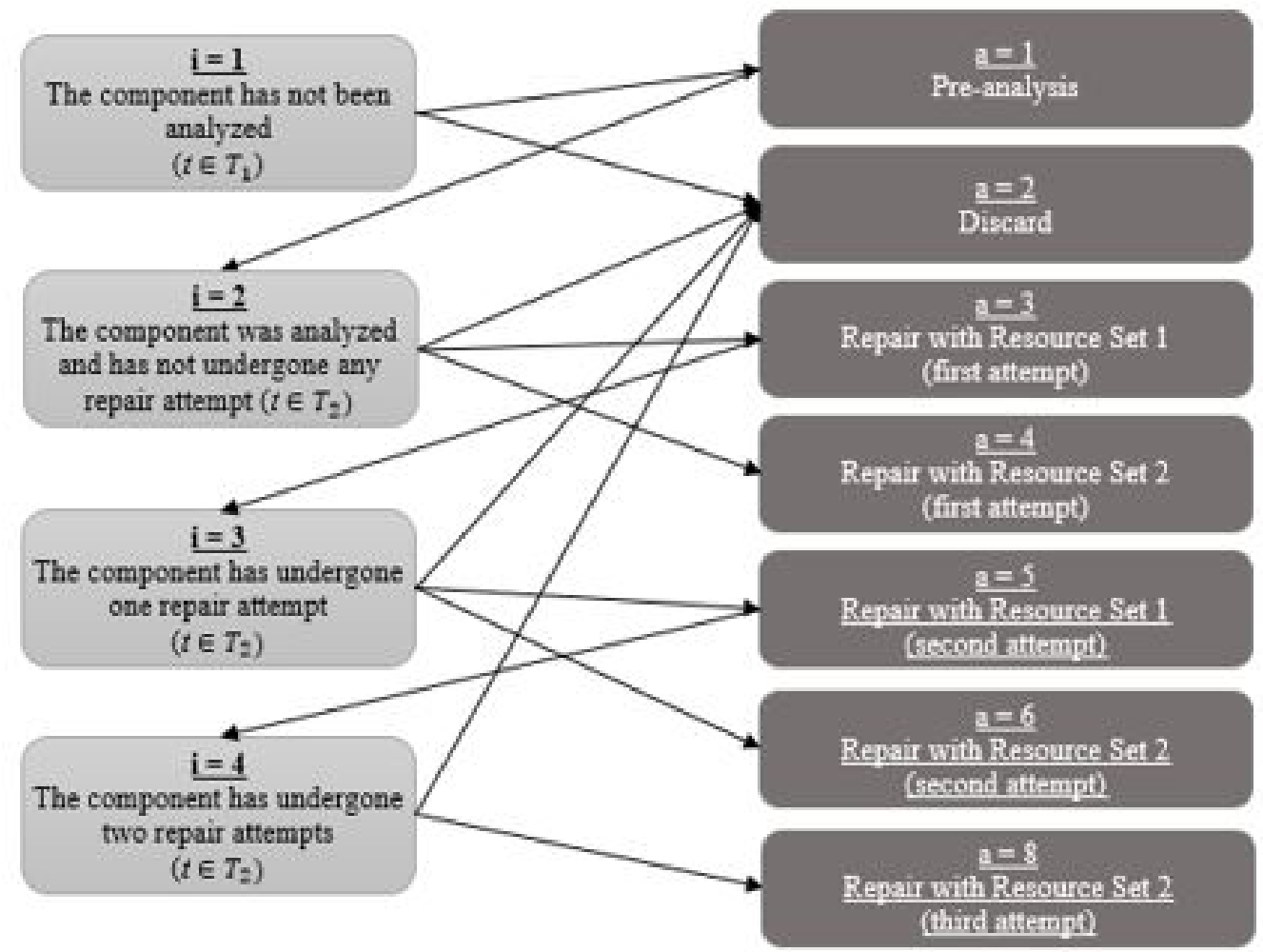

Figure 5 - All possible flows between actions (set $A$ ) and repair attempts (set $I$ ).

The first two actions correspond to the pre-analysis and disposal maintenance types, respectively, and the remaining ones to the repair maintenance type. The probability of success $\left(\alpha_{t a}\right)$ of maintenance actions $a=1, a=2$, and $a=2 N+2$ is always 1 (100\% effective). For the remaining actions, $\alpha_{t a}$ may have any value in the interval $(0,1]$. Note that maintenance action $a=2 N+$ 1 will not be allowed if $\alpha_{\mathrm{t}(2 N+1)}<1$, since it also corresponds to the last repair attempt (with Resource Set 1). 
Now, for maintenance actions, we need the resources able to perform the actions (e. g. table 1). The pair $(r, j)=h \in H,(r \in R$, and $j \in J)$, defines a local resource, which means that a resource $r$ has been deployed at site $j$. All resources have a capacity measured by available use time. Moreover, $e_{t a h}$ denotes the fraction of the capacity of a local resource $h$ consumed when action $a$ is taken for fault indication $t$. Moreover, we define $M_{h}$ as the maximum number of resources of type $r$ allowed at maintenance site $j$.

The cost function is a sum of the variable, transportation, maintenance actions and fixed costs of deploying resources at the maintenance sites. The fixed cost $f_{h}$, for each $(r, j)=h \in H$, is the cost to deploy each resource of type $r$ at maintenance site $j$. For each pair of sites $k, j \in J$ and each component $q \in Q$, the one-way transportation cost between sites $k$ and $j$ is an input data, denoted by $s_{q k j}$. The model assumes that every component sent to another site in the support network will return to the original operation site, as a repaired item or as a new one in case of discard. Thus, the objective function includes all transportation costs twice. The maintenance cost is represented as $\widehat{c}_{t a j}$, which is the variable cost of applying action $a$ to the component presenting fault indication $t$ at location $j$.

The resources may have extra capacity or not, which is useful to avoid the need to increase the quantity of a resource that would otherwise have idle capacity. For example, workers may accept working overtime. Extra capacities imply higher installation costs, but these cost increases are usually smaller than the cost to install an additional resource at the same location. The installation cost of a local resource $h \in H$ with extra capacity is denoted by $f_{h}^{\prime}$ instead of $f_{h}$. The overall capacity of a local resource $h$ with extra capacity is the product of its original capacity with the parameter $\theta_{h}>1$. Outside parties can also perform repairs. In this case, it is not necessary to own maintenance resources, but the unit cost per repair is generally higher (Brick \& Uchoa, 2009).

A solution to this problem must define the sites where those actions will take place, the number of resources of each type installed at each site to perform those actions, and to what extent to consider extra capacities for each resource. The objective is to minimize the sum of all variable costs associated with transportation and maintenance actions, and fixed costs incurred for resource installations. Note that the previous problem definition naturally allows generating a customized maintenance structure for each fault mode that occurs at each operation site, because each action performed with the same faulty component at a different maintenance site represents an additional maintenance echelon. Table 2 summarizes all model parameters.

\subsection{Example Instance}

To illustrate the model, consider a problem instance with two operation sites and another site used exclusively for maintenance $(J=\{1,2,3\}$, and $K=\{1,2\})$. Additionally, the asset $X$ has a single LRU (component 1) with one BITE indication $\left(T_{1}=\{1\}\right)$ and one fault mode $\left(T_{2}=\{2\}\right)$, containing a single SLRU (component 2) with one fault mode $\left(T_{2}=\{3\}\right)$. Thus, $Q=\{1,2\}$.

The BITE indication 1 corresponds to fault 2 in $80 \%$ of the cases $\left(\gamma_{12}=0.8\right.$, which means the faulty component was LRU 1 itself, and to fault 3 in the remaining $20 \%$ ( $\gamma_{13}=0.2$. In this 
Table 2 - Glossary of model parameters.

\begin{tabular}{|c|l|}
\hline$K$ & Set of geographical locations with operation sites $k$ \\
\hline$J$ & Set of geographical locations $j$ qualified to receive maintenance sites $(K \subseteq J)$. \\
\hline$Q$ & Set of components $q$ for all assets supported by the maintenance system \\
\hline$T_{1}$ & Set of BITE indications $t^{\prime}$ \\
\hline$T_{2}$ & Set of pre-analysis indications, or faults, $t^{\prime \prime}$ \\
\hline$R$ & Set of resource types $r$ \\
\hline$I$ & Set of repair attempt indexes $i$. \\
\hline$A$ & Set of possible maintenance actions $a$ \\
\hline$H$ & Set of local resources $h=(r, j)$ \\
\hline$f_{\mathrm{h}}$ & $\begin{array}{l}\text { Fixed cost to deploy each resource of type } r \text { with standard capacity at } \\
\text { maintenance site } j\end{array}$ \\
\hline$f^{\prime}{ }_{\mathrm{h}}$ & $\begin{array}{l}\text { Fixed cost to deploy each resource of type } r \text { with extra capacity at } \\
\text { maintenance site } j\end{array}$ \\
\hline$s_{\mathrm{qkj}}$ & Variable one-way transportation cost of component $q$ between sites $k$ and $j$ \\
\hline$\widehat{c}_{t a j}$ & $\begin{array}{l}\text { Variable cost of applying action } a \text { to the component presenting the fault } \\
\text { indication } t \text { at the location } j .\end{array}$ \\
\hline$d_{\mathrm{t}^{\prime} \mathrm{k}}$ & Number of BITE indications of type $t^{\prime}$, occurring at operation site $k$ \\
\hline$\lambda^{\mathrm{t} "}$ & Failure rate of fault $t^{\prime \prime}$ \\
\hline$\lambda^{\mathrm{q}}$ & Failure rate of component $q$ \\
\hline$e_{\mathrm{tah}}$ & $\begin{array}{l}\text { Fraction of the capacity of the resource type } r \text { consumed when action } a, \text { for } \\
\text { fault indication } t, \text { is performed at maintenance site } j\end{array}$ \\
\hline$\alpha^{\mathrm{ta}}$ & Success probability for maintenance type $a$ on fault indication $t$. \\
\hline$M_{\mathrm{h}}$ & Maximum number of resources of type $r$ allowed at maintenance site $j$ \\
\hline$\theta_{h}>1$ & Multiplying factor for extra capacity resources \\
\hline & \\
\hline
\end{tabular}

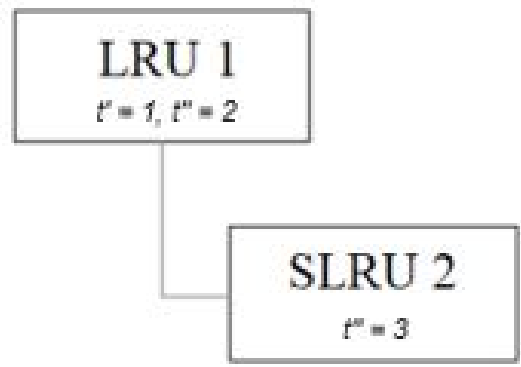

Figure 6 - Asset $X$ tree structure and fault modes.

case, the faulty component is SLRU 2. We assume that the Resource Sets 1 and 2 are $75 \%$ and $100 \%$ effective (low and high effectiveness), respectively, in repairing every fault indication ( $\alpha_{23}=\alpha_{25}=\alpha_{33}=\alpha_{35}=0.75$, and all remaining $\alpha_{t a}$ 's are equal to 1$)$. Up to 3 repair attempts are considered $(N=3)$. 
Fig. 7 illustrates an example solution for this instance through a graph whose nodes are disposed in a table. In this table, rows represent sites and columns represent alternate repair attempt indices and the actions taken between them.

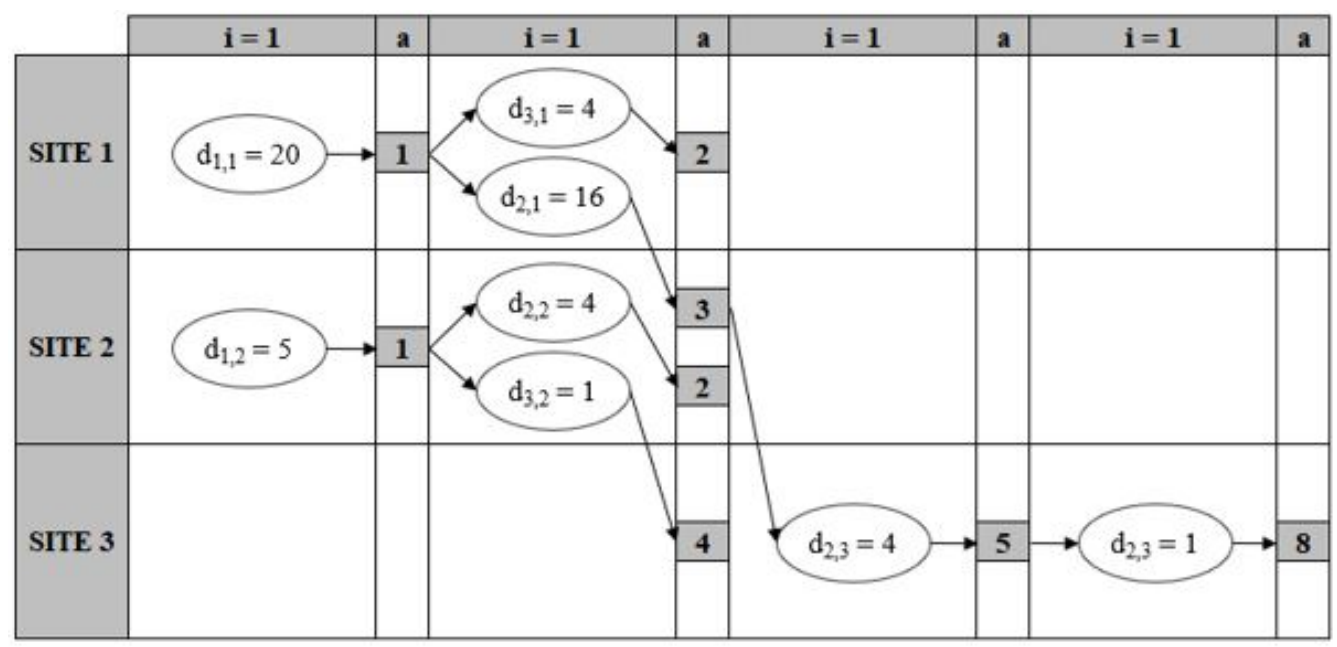

Figure 7 - Example of a maintenance network.

Arcs indicate both the assignment of fault indications to actions and the generation of new fault indications, resulting from previous actions. We use the notation $d_{t j}$ to denote the number of occurrences of fault indication $t \in T$ (BITE or precise) at site $j \in J$, which is not an input to the model when it results from the pre-analysis actions.

In Fig. 7, for example, historically there were identified 20 failures for asset $\mathrm{X}$ in operational site 1. Each failure was pre-analyzed, and 16 of them were due to defect 2 (in LRU 1) and 4 due to defect 3 (in SLRU 2). These four from defect 3 were discarded (action 2), and this part of the flow ends, and the remaining 16 underwent maintenance action with $75 \%$ efficiency resources in operation site 2. So, 12 were fixed (and the flow ends), and 4 (25\%) went to maintenance site 3 to undergo a second repair attempt, again using a 75\% efficient equipment. This fixed 3 units, and one unit continued the flow. Finally, this unit was repaired with a $100 \%$ efficient resource (third repair attempt), and the flow was completed.

\section{FLOW-BASED REPRESENTATION}

To solve this problem, we proposed a flow-based representation as a network over a bipartite directed graph where the first partition represents demands and the second one represents possible actions. A demand node $l \in L$ is a triplet $(k, t, i)$, where $k$ is an operation site, $t$ a fault indication, and $i$ a repair attempt index. For each node $l=(k, t, i), d(l)$ is defined as follows. If $t$ is a BITE indication $t^{\prime}$, then $i=1$, and $d(l)=d\left(\left(k, t^{\prime}, i\right)\right)$ is equal to $d_{t^{\prime} k}$, that is, the total number of occurrences of such indications at site $\mathrm{k}$. Otherwise, $d(l)$ is set to zero, since other maintenance demands are represented by the flows incident to $l$. Moreover, each action node $v \in V$ is a triplet $(j, t, a)$, where 
$j$ is a maintenance site, $t$ is a fault indication, and $a$ is a maintenance action. The underlying graph is defined as $G=\left(L \cup V, A=A_{L} \cup A_{V}\right)$, with $L \cap V=\emptyset$, where $A_{L}=\{(l, v) \in A \mid l \in L, v \in V\}$, and $A_{V}=\{(v, l) \in A \mid v \in V, l \in L\}$.

To illustrate the graph's construction, let us consider the example given in Subsection 2.1 and the solution of Fig. 7.

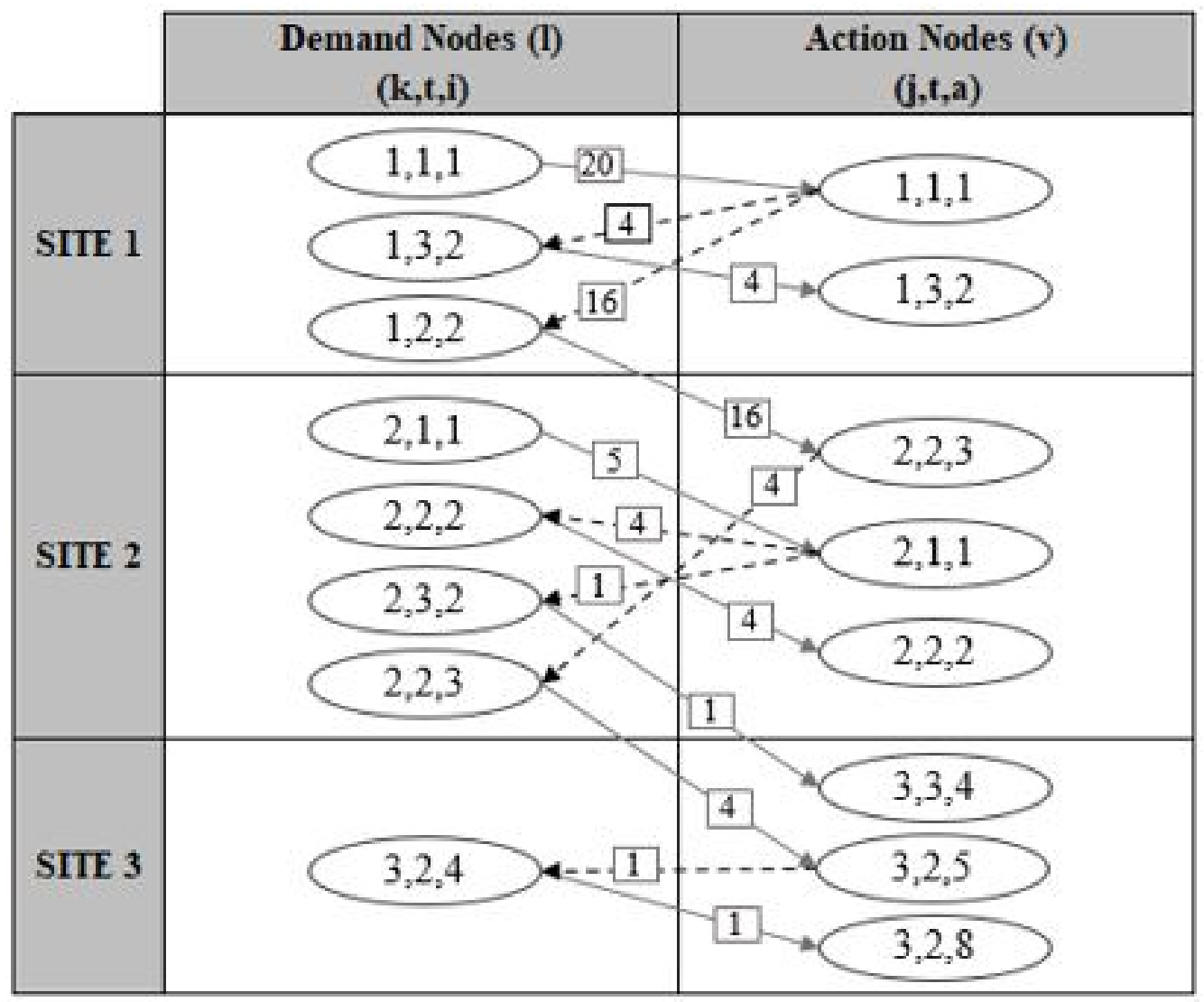

Figure 8 - Example of a maintenance network using a flow-based representation.

Flows in this graph represent feasible solutions to the problem. Each flow unit that passes through an arc of $A_{L}$ indicates that a component with the maintenance demand described by its tail node is submitted to the action described by its head node. Additionally, each flow unit that passes through an arc of $A_{V}$ indicates that a component that was submitted to the action described by its tail node has a new maintenance demand described by its head node.

This solution is exactly the same shown in Fig. 7, however represented in another format. In this case, $L$ is composed of every node $(k, t, i)$, for $k \in\{1,2,3\}, t \in\{1,2,3\}$, and $i \in\{1,2,3,4\}$. Node $(3,1,1)$ does not exist because there is no original demand being generated at site 3 , which is used only for maintenance. The demands are $d((1,1,1))=\mathrm{d}_{1,1}=20$ and $d((2,1,1))=d_{1,2}=5$. In 
this figure, the numbers in the arrows represent the number of flows that pass through them. The few depicted arcs and nodes are the ones through which there are non-zero flows passing. Note that representing all the nodes and arcs would make the picture unintelligible.

For example, the arc from the demand node $(1,1,1)$ to the action node $(1,1,1)$ means that all 20 components from site 1 that present the BITE indication 1 are subject to pre-analysis at the same site. These pre-analyses indicate that 16 of those components present fault 2 in a subcomponent, and the remaining 4 present fault 3 , generating the new demand nodes $(1,2,2)$ and $(1,3,2)$. Node $(1,3,2)$ is connected to action node $(1,3,2)$, which indicates that the corresponding 4 components are discarded at the same site, and the other 16 components represented by node $(1,2,2)$ undergo a repair attempt with Resource Set 1 at site 2, which is indicated by the connection with action node $(2,2,3)$.

\section{MIXED INTEGER PROGRAMMING FORMULATION}

To formulate the problem as a MIP, the decision variable $x_{l v}$ represents the quantity of flows passing through an arc $(l, v)$ in a solution represented as described in the previous section. The cost to send this flow through the arc $(l, v)$ is $c_{l v}$, which consists of the costs to transport the corresponding component from node $l$ to node $v$, perform the corresponding maintenance action at $v$ and return the component to node $l$. For each $l=(k, t, i), v=(j, t, a)$, and $q$ denoting the component associated with $t, c_{l v}$ is calculated as $2 s_{q k j}+\widehat{c}_{t a j}$.

Resource constraints limit the flows into the network, which differentiate this model from the classic minimum cost flow model. The required number of units of a local resource type $h$, without and with extra capacity, to be installed at a site $j$, is defined by the decision variables $y_{h}$ and $y_{h}^{\prime}$, respectively, where $h=(r, j) \in H$. The parameter $u_{h}(v)$ is the fraction of the capacity of a resource $\mathrm{r}$ (without extra capacity) that is consumed by each flow unit passing through the node $v \in V$. For each $v=(j, t, a)$ and $h=(r, j), u_{h}(v)=e_{\text {tah }}$. Note that $u_{h}(v)=0$ whenever the locations associated with $v$ and $h$ are distinct. This is suitable to compute the total usage of $h$ summing over all $v$ without requiring the $h$ and $v$ are associated to the same location.

As previously mentioned, only one action option is allowed for each fault indication that occurs in each location. To model this feature, a binary decision variable $z_{l v}$ is defined, so that a non-zero flow is allowed to pass through the $\operatorname{arc}(l, v)$ only when $z_{l v}=1$. Otherwise, when $z_{l v}=0$, such flow is forbidden.

Given an $\operatorname{arc}(l, v)$, where $l=(k, t, i)$ and $v=(j, t, a)$, if $t$ is a BITE indication, or the effectiveness of the action $a$ is not $100 \%$, it means that the demands originated in the node $l \in L$ that have undergone an action in node $v \in V$ may generate new demands in other nodes associated with the maintenance site $\mathrm{j}$. In both cases, the parameter $\beta_{l v w}$ denotes the fraction of the maintenance requests originated in the node $l \in L$ and that have undergone an action in the node $v \in V$ that generates a new demand in the node $w=\left(j, t^{\prime}, i^{\prime}\right) \in L$. Recall that the parameter $\gamma_{t t^{\prime}}$ represents the probability that the pre-analysis indication $t^{\prime}$ results from a pre-analysis action performed on a component with the BITE indication $t$. Thus, if $t$ is a BITE indication and the action taken is 
pre-analysis $(a=1)$, then $\beta_{l v w}$ is set to $\gamma_{t t^{\prime}}$ for all $w=\left(j, t^{\prime}, i^{\prime}\right) \in L$, with $i^{\prime}=2$, since no repair attempt has been made. Moreover, if the effectiveness of the action $a$ is not $100 \%$, then $\beta_{l v w}$ is set to $1-\alpha_{t a}$ only for $w=\left(j, t^{\prime}, i^{\prime}\right) \in L$, where $t^{\prime}=t$, and $i^{\prime}$ is compatible with the action $a$ just taken in node $v$ considering the number of previous attempts and the resource sets already used. For all other cases, $\beta_{l v w}$ is set to zero.

The only decision variables are $x_{l v}, y_{h}, y_{h}^{\prime}$ and $z_{l v}$. All the other quantities are given. Thus, the MIP formulation starting from its objective function is the following:

$$
\text { Minimize } \sum_{(l, v) \in A_{L}} c_{l v} x_{l v}+\sum_{h \in H}\left(f_{h} y_{h}+f_{h}^{\prime} y_{h}^{\prime}\right)
$$

Every demand or amount of flow that reaches a node $l$ goes to a node $v$ to receive a maintenance action. This leads to the following flow conservation constraints:

$$
\sum_{v:(l, v) \in A_{L}} x_{l v}=\sum_{v:(v, l) \in A_{V}} x_{v l}+d(l), l \in L(1)
$$

From the $x_{l v}$ fault indications originated in node $l \in L$ that have undergone an action in node $v \in V, \beta_{l v w} x_{l v}$ generates a new fault indication in node $w \in L$. Hence, the following constraints also apply:

$$
x_{v w}=\sum_{l:(l, v) \in A_{L}} \beta_{l v w} \cdot x_{l v},(v, w) \in A_{v}(2)
$$

The following constraints prevent more than a non-zero flow from each demand node $l \in L$, where $U_{l v}$ denotes an upper bound on the maximum flow that can pass through an arc $(l, v)$ in any feasible solution.

$$
\begin{gathered}
x_{l v} \leq z_{l v} . U_{l v},(l, v) \in A_{L}(3) \\
\sum_{v:(l, v) \in A_{L}} z_{l v} \leq 1, l \in L(4)
\end{gathered}
$$

The following constraints ensure that the capacity usage of each resource at each site does not exceed the corresponding installed capacity.

$$
\sum_{(l, v) \in A_{L}} u_{h}(v) x_{l v} \leq y_{h}+\theta_{h} y_{h}^{\prime}, h \in H(5)
$$

Finally, the domains of all decision variables have the following constraints:

$$
\begin{gathered}
x_{l v} \geq 0,(l, v) \in A(6) \\
y_{h}, y_{h}^{\prime} \in\left\{1,2, \ldots, M_{h}\right\} h \in H(7)
\end{gathered}
$$




$$
z_{l v} \in\{0,1\}(l, v) \in A_{L}(8)
$$

\section{EXPERIMENTS}

In this section, we report experiments with several instances generated from a base test case detailed in Appendix A.

It is worth mentioning that no previously proposed problem found in the literature considers all the features included in the present optimization model. Thus, the comparison with other methods forms the literature is not possible. For this reason, new test cases are devised to evaluate the benefit of using the proposed formulation.

Each test case evaluates the potential gain obtained through each particular capability of the proposed model. A program implemented in MS Excel Visual Basic (VBA) handled the model data. CPLEX solved the resulting MIP instances through a programming interface with VBA provided by the UFFLP library (Pessoa \& Uchoa, 2011).

\subsection{Test Cases and Instances}

All generated instances have the same dimensions, summarized in Table 3.

Table 3 - Instance Dimensions.

\begin{tabular}{|l|l|l|}
\hline Parameter & Cardinality & Comments \\
\hline Operation sites & $|K|=10$ & $\begin{array}{l}\text { 10 operating sites, and 5 sites exclusively for } \\
\text { maintenance }\end{array}$ \\
\hline Maintenance sites & $|J|=15$ & $\begin{array}{l}\text { The 4 first indenture components are LRUs and } \\
\text { the remaining 6 highest-level indenture } \\
\text { components are SLRUs. }\end{array}$ \\
\hline Components & $|Q|=10$ & \\
\hline Fault indications & $|T|=20$ & $\left|T_{1}\right|=4$ \\
$\left|T_{2}\right|=16$ & $|R|=6$ & \\
\hline Resource types & $|R|=6$ & \\
\hline
\end{tabular}

In order to verify formulation capabilities, we used the following seven test cases:

1. Complete (COMP) considers the problem as presented, with resource configurations including two levels (high and low) of both effectiveness and capacity, and the possibility to deploy pre-analysis resources at both operation and maintenance sites;

2. No Pre-Analysis (NPA) is equal to COMP, but with no pre-analysis allowed at the operation site where the failure occurred. This corresponds to the usual situation where operation 
sites do not have resources other than those needed for operation and replacement of a few components (LRU);

3. High-Effectiveness (HEF) is equal to COMP, with the exception that it only considers high-effectiveness $(100 \%)$ resource sets;

4. Low- Effectiveness (LEF) is equal to COMP, with the exception that it only considers low-effectiveness $(75 \%)$ resource sets;

5. No Extra Capacity (NEC) is equal to COMP, with the exception that resources may not have extra (high) capacity;

6. Pre-Installed Facilities (PIF) is equal to COMP, with the exception that two facilities (which are modeled as one of the required resource types) already exist at some maintenance sites (zero facility cost); and

7. Outsourcing (OUT) is equal to COMP, with the exception that two maintenance sites are outsourced, meaning that the action costs are bigger than at other sites, but require no installed resources (zero fixed resource cost).

We generated 10 different instances to cover each test case with a broad spectrum of data characteristics, based on the data and assumptions presented in Appendix A. The following problem characteristics varied randomly among the instances, according to uniform probability distributions with the ranges shown in Appendix A:

- fraction of resource capacity consumed by each maintenance action $\left(e_{t a h}\right)$;

- maintenance action costs $\left(\widehat{c}_{t a j}\right)$;

- number of occurrences of BITE indication types $\left(d_{k t}\right)$;

- transportation costs $\left(s_{q k j}\right)$; and

- facility installation costs and pre-analysis test equipment cost $\left(f_{h}\right)$;

For each randomly generated instance, all seven test cases are applied. Resulting comparisons allowed verifying how the flow behaves in these different situations, and how these changes affect life cycle costs. The reported results consider:

1. Repair policy decisions (pre-analysis, disposal or repair)

2. Total life cycle costs;

3. Maintenance network (number of echelons) for each fault indication $t$; 


\subsection{Experimental Results}

For all runs, we used a PC with Intel Core i5 processor and 4 GB of memory, with a 3600 seconds limit on running time. The optimality GAP varied from $0.01 \%$ (for solutions considered as optimal) to a maximum of $4.85 \%$. Optimality was proved for $40 \%$ of the solutions and $18.57 \%$ had a gap higher than $2 \%$. For some instances, the percent difference between the total cost of ownership (TCO) and that of the base test case (COMP) was lower than the corresponding optimality GAPs. In these cases, we solved the instances again with increased limits on their running times to reduce the GAPs. This was the case for NEC (7200s) and PIF (9000s) with instance 1, and PIF (9000s), with instance 6.

Although this is not the main objective of this study, we consider that the model performance was acceptable for the tested problem size.

The main highlights of the test results are:

1. The possibility of doing pre-analysis at operational sites and of choosing between two different resource sets (considering effectiveness and capacity) were indeed relevant for cost reduction;

2. The use of extra capacity did not have a considerable impact on total costs;

3. Optimization did in fact generate networks with up to 4 echelons;

4. Even for instances containing sites with zero construction costs (pre-installed and outsourced), in some cases the model chose to construct and install additional maintenance sites.

Fig. 9 shows an example of a maintenance structure generated as output for COMP, instance 5. In this figure, duplicated nodes representing sites, and their connection by arrows, represent fictitious transportation to depict sequences of actions applied to components at the same site. Number sequences, separated by commas, placed near arrows and nodes, represent faults and BITE indications, respectively. This figure shows an example of different actions happening at the same site (site 9) to handle demands generated at other sites. The demand for pre-analysis at site 9 originated from sites 6, 7, 8, 9 and 10. This demand, after analyzed, resulted in two different actions at the same site: repair with low effectiveness for faults 5, 7, 8, 70, 15, 17 and 19, and repair with high effectiveness for faults $6,9,11,12,13,14,16,18$ and 20 . In sequence, new sites 3 and 9 receive the remaining faulty components, and repair them with high-effectiveness equipment.

The use of pre-analysis at operation sites resulted in the selection of some SLRUs as LRUs, while others became SRUs. For example, in COMP, instance 3, SLRU 5 at sites 2, 6, 7 and SLRU 10 at site 8 became SRUs. All other SLRUs not mentioned previously became LRUs. For NPA, which prohibits pre-analysis at the same site where the BITE indication occurred, all SLRUs are SRUs. 
Table 4 presents the results concerning the TCO for each test case and each instance. For all cases other than COMP, the data shown are the percent differences with respect to the TCO of the corresponding COMP instances.

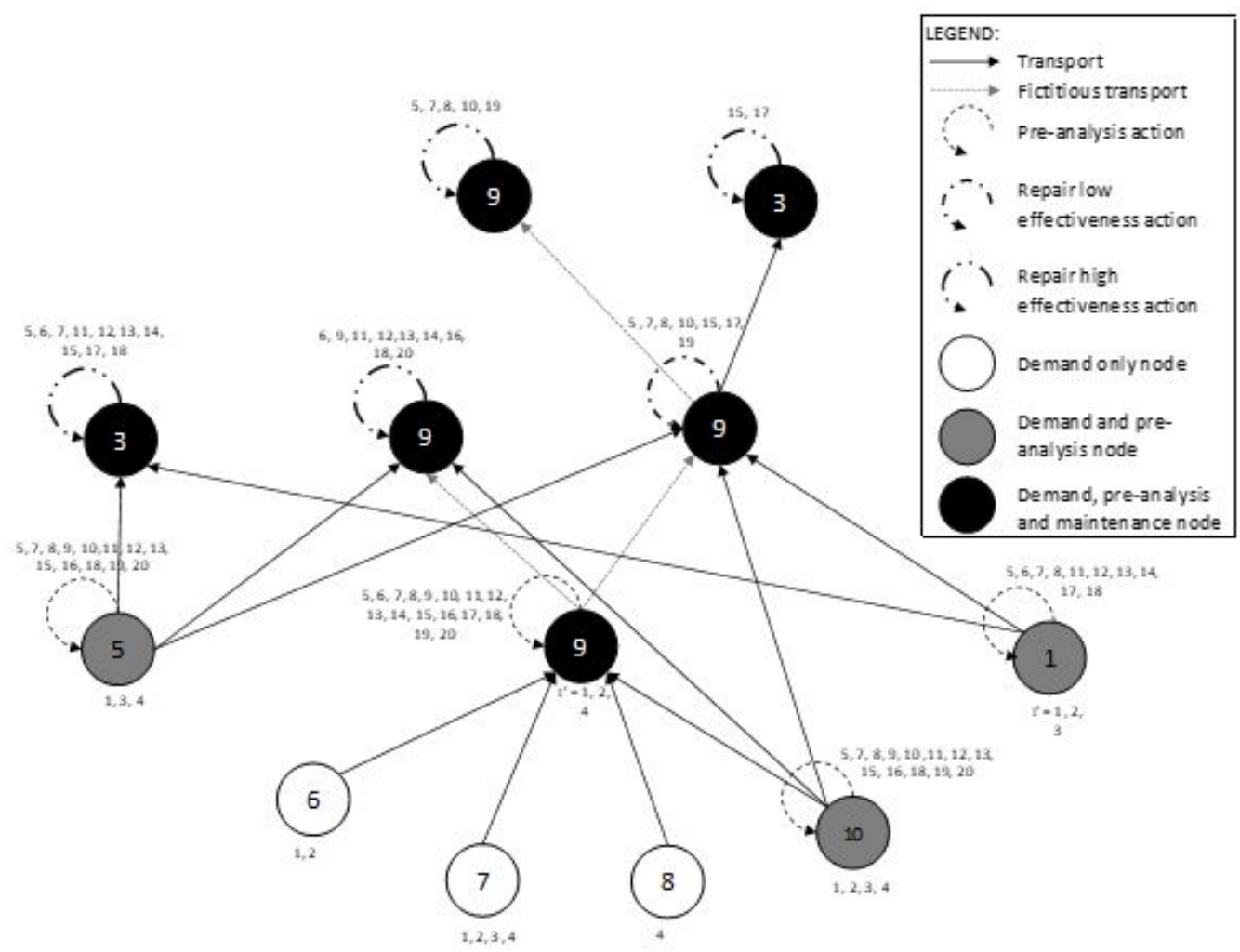

Figure 9 - Different maintenance actions occurred at site $k=9$ to handle demands coming from different sites (instance 5 for COMP test case).

Since COMP considers all modelling features, one would expect the TCOs associated with NPA, HEF, LEF and NEC to be higher. The results in Table 4 confirm this assertion.

To the contrary, PIF supposedly produces lower TCOs, due to the cost reductions obtained by using pre-installed facilities. This behavior occurred for all instances, except for instance 6 , which had a TCO for PIF $0.03 \%$ bigger than the one for COMP. However, in this case, even after increasing the running time to 9000 seconds, the GAP for PIF (2.13\%) remained much bigger than the cost percent difference $(0.03 \%)$ and no conclusion could be drawn. What may be surprising is that for four instances, the best solution for PIF disregarded some existing zero-cost facilities and opted to construct new ones, incurring the added costs.

The comparison of COMP with OUT, however, is not so obvious, since there are many tradeoffs involved. Nevertheless, results showed cost reductions in all instances. Of course, the results for 
Table 4 - Total costs of ownership (TCO) for test case COMP and percentage variations for the other test cases.

\begin{tabular}{|c|c|c|c|c|c|c|c|}
\hline Instance & COMP (\$million) & NPA & HEF & LEF & NEC & PIF & OUT \\
\hline $\mathbf{1}$ & 279.66 & $6.07 \%$ & $0.39 \%$ & $\mathbf{1 3 . 4 2 \%}$ & $0.76 \%$ & $-1.30 \%$ & $-1.66 \%$ \\
\hline $\mathbf{2}$ & 323.74 & $7.27 \%$ & $6.67 \%$ & $\mathbf{2 4 . 9 7 \%}$ & $0.14 \%$ & $-11.25 \%$ & $-0.80 \%$ \\
\hline $\mathbf{3}$ & 173.50 & $4.93 \%$ & $5.45 \%$ & $\mathbf{2 5 . 4 4 \%}$ & $0.40 \%$ & $-13.84 \%$ & $-0.75 \%$ \\
\hline $\mathbf{4}$ & 215.20 & $12.90 \%$ & $3.79 \%$ & $\mathbf{2 1 . 1 1 \%}$ & $0.31 \%$ & $-18.85 \%$ & $-1.28 \%$ \\
\hline $\mathbf{5}$ & 226.69 & $3.01 \%$ & $0.82 \%$ & $\mathbf{3 2 . 5 3 \%}$ & $0.37 \%$ & $-6.01 \%$ & $-1.54 \%$ \\
\hline $\mathbf{6}$ & 252.43 & $5.09 \%$ & $14.99 \%$ & $\mathbf{2 0 . 5 8 \%}$ & $0.00 \%$ & $0.03 \%$ & $-0.18 \%$ \\
\hline $\mathbf{7}$ & 160.96 & $4.57 \%$ & $4.64 \%$ & $\mathbf{1 9 . 9 2 \%}$ & $0.53 \%$ & $-7.49 \%$ & $-1.40 \%$ \\
\hline $\mathbf{8}$ & 152.82 & $7.52 \%$ & $3.74 \%$ & $\mathbf{2 4 . 4 8 \%}$ & $0.05 \%$ & $-18.22 \%$ & $-1.83 \%$ \\
\hline $\mathbf{9}$ & 187.33 & $2.87 \%$ & $6.86 \%$ & $\mathbf{2 0 . 0 6 \%}$ & $0.09 \%$ & $-9.55 \%$ & $-1.86 \%$ \\
\hline $\mathbf{1 0}$ & 178.64 & $13.06 \%$ & $11.32 \%$ & $\mathbf{2 6 . 7 5 \%}$ & $0.48 \%$ & $-22.89 \%$ & $-2.11 \%$ \\
\hline Average & 215.10 & $6.73 \%$ & $5.87 \%$ & $\mathbf{2 2 . 9 3 \%}$ & $0.31 \%$ & $-10.94 \%$ & $-1.34 \%$ \\
\hline
\end{tabular}

PIF and OUT costs depend on which locations have pre-installed facilities or are outsourced. For each instance, we selected randomly two sites for this purpose (and kept them the same for all test cases). As expected, PIF presented lower TCOs than OUT in most cases, as action costs were not increased. Using outsourcing, however, was always beneficial, although the differences with respect to COMP were very small (maximum of $2.11 \%$ ). Among the 10 OUT instances, in only one of them the choice was not to use the two available outsourcing suppliers. However, in all of them the solver chose to open other facilities in addition to the outsourcing ones.

Regarding the remaining comparisons among test cases other than COMP, LEF represented the highest cost for all instances, which appear in boldface Table 4. NPA and HEF always alternated positions when ranking the TCO. Each one beat the other 5 times (5 instances). Therefore, the impacts of using only $100 \%$ effective resources and not allowing pre-analysis at operational sites depend directly on the characteristics of the instance. For instance 6, COMP and NEC had exactly the same result. This happened because the optimal solution for COMP considered no usage of extra capacity.

Overall, the results were very consistent and confirmed the expectations: increasing facility cost reduces the number of maintenance facilities created. Increasing pre-analysis equipment costs reduces the number of operation sites where performing pre-analysis is worthwhile. The same occurs when transportation costs decrease.

Table 5 confirms the formulation's ability to generate the maintenance network as an output. For LEF, since it uses only resources that are not $100 \%$ effective, the solution is more likely to have a fourth echelon, as observed in Table 4. This happened in 5 out of 10 LEF instances. For HEF, which uses only $100 \%$ effective resources, rework cannot occur, so in most of the instances the maintenance network had only two echelons. Four echelons also appeared in $30 \%$ of the instances for PIF and OUT. 
Table 5 - A more thorough analysis of instance 7.

\begin{tabular}{|c|c|c|c|c|c|c|c|c|c|c|c|c|}
\hline TC & $\mathrm{C}$ & $\mathbf{S}$ & $\overline{R T}$ & G & MS & O & MA & PS & FC & PC & $\overline{D F}$ & $\mathbf{E}$ \\
\hline COMP & 161,0 & Feas & 3600 & $0.02 \%$ & 3,9 & - & $\begin{array}{l}\text { Repair low } \\
\text { efficiency } 75 \% \\
\text { (1st attempt) } \\
\text { Repair high } \\
\text { efficiency } \\
100 \% \text { (1st and } \\
\text { 2nd attempt) }\end{array}$ & $\begin{array}{l}1,2,3, \\
4,5,7, \\
8,9,10\end{array}$ & 10.8 & 0.15 & $1 / 590$ & 2 \\
\hline NPA & 168.3 & Feas & 3600 & $0.22 \%$ & 3,9 & - & $\begin{array}{l}\text { Repair low } \\
\text { efficiency } 75 \% \\
\text { (1st attempt) } \\
\text { Repair high } \\
\text { efficiency } \\
100 \% \text { (1st and } \\
\text { 2nd attempt) }\end{array}$ & 3,9 & 10.8 & 0.15 & $1 / 590$ & 3 \\
\hline HEF & 168.4 & Opt & 72 & $0.01 \%$ & 3,9 & - & $\begin{array}{l}\text { Repair high } \\
\text { efficiency } \\
100 \%(1 \mathrm{st} \\
\text { attempt) }\end{array}$ & $\begin{array}{l}1,2,3, \\
4,5,7, \\
8,9,10\end{array}$ & 10.8 & 0.15 & $1 / 590$ & 2 \\
\hline LEF & 193.0 & Opt & 204 & $4.44 \%$ & 3,9 & - & $\begin{array}{l}\text { Repair low } \\
\text { efficiency } 75 \% \\
\text { (1st and 2nd } \\
\text { attempt) } \\
\text { Discard }\end{array}$ & $\begin{array}{l}1,2,3, \\
4,5,7, \\
8,9,10\end{array}$ & 10.8 & 0.15 & $1 / 590$ & 4 \\
\hline NEC & 161.8 & Feas & 3600 & $5.70 \%$ & 3,9 & - & $\begin{array}{l}\text { Repair low } \\
\text { efficiency } 75 \% \\
\text { (1st attempt) } \\
\text { Repair high } \\
\text { efficiency } \\
100 \% \text { (1st and } \\
\text { 2nd attempt) }\end{array}$ & $\begin{array}{l}1,2,3, \\
4,5,7, \\
8,9,10\end{array}$ & 10.8 & 0.15 & $1 / 590$ & 3 \\
\hline PIF & 148.9 & Feas & 3600 & $0.04 \%$ & $\begin{array}{l}12, \\
13\end{array}$ & $\begin{array}{l}12, \\
13\end{array}$ & $\begin{array}{l}\text { Repair low } \\
\text { efficiency } 75 \% \\
\text { (1st and 2nd } \\
\text { attempt) } \\
\text { Repair high } \\
\text { efficiency } \\
100 \% \text { (1st and } \\
\text { 2nd attempt) } \\
\text { Discard }\end{array}$ & $\begin{array}{l}1,2,3 \\
4,7,8 \\
9,10 \\
13\end{array}$ & 10.8 & 0.15 & $1 / 590$ & 4 \\
\hline OUT & 158.7 & Feas & 3600 & $0.28 \%$ & $\begin{array}{l}9, \\
12, \\
13\end{array}$ & $\begin{array}{l}12, \\
13\end{array}$ & $\begin{array}{l}\text { Repair low } \\
\text { efficiency } 75 \% \\
\text { (1st attempt) } \\
\text { Repair high } \\
\text { efficiency } \\
100 \% \text { (1st and } \\
\text { 2nd attempt) }\end{array}$ & $\begin{array}{l}1,2,3, \\
4,5,7, \\
8,9,10\end{array}$ & 10.8 & 0.15 & $1 / 590$ & 3 \\
\hline
\end{tabular}

$\mathrm{TC}=$ Test case $; \mathrm{MA}=$ Maintenance actions $; \mathrm{C}=$ Total cost $(\$$ million$) ; \mathrm{PS}=$ Pre-analysis sites $; \mathrm{S}=$ Solution status $(\mathrm{Fea}=\mathrm{Feasible} / \mathrm{Opt}=$ Optimal); FC = Facility cost (R \$ million); RT = Resolution time; $\mathrm{PC}=$ Pre-analysis equipment cost $(\mathrm{R} \$$ million $) ; \mathrm{G}=\mathrm{Solution} \mathrm{GAP} ; \mathrm{DF}$ $=$ Distance factor for transportation cost MS = Maintenance sites; $\mathrm{E}=$ Echelons; $\mathrm{O}=$ Pre-installed or outsourcing sites. 
Finally, Fig. 10 depicts an example of a four-echelon maintenance network structure generated for PIF instance 7. It is also possible to observe the occurrence of all maintenance actions: preanalysis, repair with high and low effectiveness, and discard.
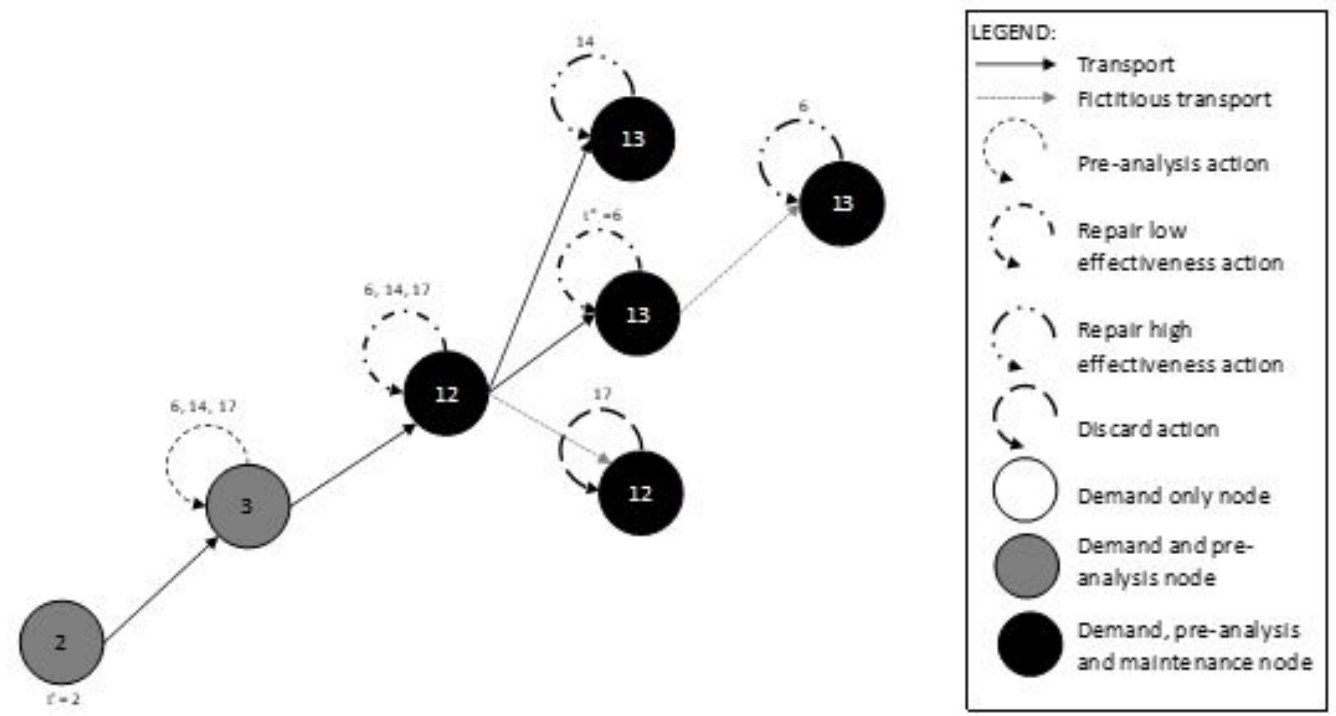

Figure 10 - Four-echelon maintenance structure generated for BITE indication 2, when occurring at site 2, in PIF instance 7.

\section{CONCLUSIONS}

This paper proposes an extended LORA model with new capabilities not found previously in the literature, which we show are relevant for cost reductions. These capabilities are:

1. The possibility to choose between resource sets with different effectiveness and costs to perform the same action.

2. The possibility to deploy resources to perform pre-analyses before deciding on which maintenance action to perform. Cost reductions result from avoiding maintenance actions involving more expensive, voluminous and/or heavier items. This characteristic leads naturally to the solution of the LRU definition problem.

3. The possibility to choose between two different resource sets with different capacities to perform the same action. Cost reductions result from avoiding installation of additional expensive resources that would otherwise remain idle most of the time.

4. The possibility to include the construction cost of facilities when solving the location problem. This feature results in reductions of the cost and quantity of needed facilities. 
5. The possibility to generate maintenance networks with up to four echelons. The maintenance network is a model output rather than an input and is a direct consequence of model assumptions, as well demand and resource characteristics.

Experiments covering seven different test cases, with the use of 10 different randomly generated instances for each, demonstrated the relevance of these model capabilities for cost reductions.

The approach also incorporates most of the features encountered in previous models, such as outsourcing, facilities location, capacitated and non-capacitated resources and unsuccessful repair probabilities. Parameters can depend on demand origin and the location of the service facility.

It is also important to point out that this model applies equally to health systems, defining the location of health centers, medium and large hospitals and reference centers for various kinds of health issues. This is possible by the analogy that exists between fault indications and health problem diagnostics and between faults and health problems.

Future works may include more general capabilities for BITE (for instance, fault indication in high indenture level LRU, SLRU or SRU), time-dependent failure rates, joint optimization of level of repair (LOR) and preventive maintenance scheduling and joint optimization of asset availability and support system total cost of ownership.

\section{Acknowledgements}

Artur Alves Pessoa received support from Brazil's Conselho Nacional de Desenvolvimento Científico e Tecnológico (CNPq), grant number 306522/2016-0.

\section{References}

[1] Alfredsson P. 1997. Optimization of multi-echelon repairable item inventory systems with simultaneous location of repair facilities. European Journal of Operational Research, 99(3): 584-595.

[2] BARROS LL. 1998. The optimization of repair decisions using life-cycle cost parameters. IMA Journal of Mathematics Applied in Business and Industry, 9(4): 403-413.

[3] Barros L \& Riley M. 2001. A combinatorial approach to level of repair analysis. European Journal of Operational Research, 129, 242-251.

[4] Basten RJi, Schutten JMJ \& VAn der Heijden MC. 2009. An efficient model formulation for level of repair analysis. Annals of Operations Research, 172(1): 119-142.

[5] BAsten RJi, van Der Heijden MC \& SChutten JMJ. 2011a. A minimum cost flow model for level of repair analysis. International Journal of Production Economics, 133(1): 233-242. 
[6] Basten RJi, van der Heijden MC \& Schutten JMJ. 2011b. Practical extensions to a minimum cost flow model for level of repair analysis. European Journal of Operational Research, 211(1): 333-342.

[7] BAsten RJI, van DER HeiJden MC \& SCHUTten JMJ. 2012. Joint optimization of level of repair analysis and spare parts stocks. European Journal of Operational Research, 222(3): 374-483.

[8] BRICK ES \& UCHOA E. 2009. A facility location and installation or resources model for level of repair analysis, European Journal of Operational Research, 192(2): 479-486.

[9] Basten RJi, van der Heijden MC, Schutten JMJ \& Kutanoglu E. 2012. An approximate approach for the joint problem of level of repair analysis and spare parts stocking. Annals of Operations Research, 224(1): 121-145.

[10] Buachera T, KishK M \& Power L. (2010). Level of Repair Analysis based on Genetic Algorithm with Tabu Search. Proceedings of the World Congress on Engineering 2010 Vol III. Available at: http://www.iaeng.org/publication/WCE2010/WCE2010_ pp2166-2172.pdf. Accessed 06 August 2019.

[11] Cassady CR, Murdock JR WP \& POHL EA. 2001, Selective maintenance for support equipment involving multiple maintenance actions. European Journal of Operational Research, 129(2): 252-258.

[12] Crabtree JW \& Sandel BC. 1989. Army Level of Repair Analysis 1989. Logistic Spectrum, Summer: 27-31.

[13] Drees R.\& Young N. 2004. Role of BIT in Support System Maintenance and Availability. IEEE Aerospace and Electronic Systems Magazine, 19(8): 3-7.

[14] FAN J, GuO L, YANG Y \& KANG R. 2013. EBO optimization considering the joint of lora and spare stocks. Chemical Engineering Transactions, 33: 631-636.

[15] GAPSO. 2015. Integrando Programação Inteira Mista e Planilhas de Cálculo de forma simples e acessível (Integrating Mixed Integer Programming and Spreadsheets in a simple and accessible way). Website Gapso. Available at: http://www.gapso.com.br/ufflp/. Accessed 06 August 2019.

[16] Ghaddar B, SAKR N \& Asiedu Y. 2016. Spare parts stocking analysis using genetic programming. European Journal of Operational Research, 252(1) 136-144.

[17] GUO L, FAN J, WEN M \& KANG R. 2015. Joint optimization of LORA and spares stocks considering corrective maintenance time. Journal of Systems Engineering and Electronics, 26 (1): 85-95. 
[18] Lins ID \& DRoguetT EL. 2009. Multiobjective optimization of availability and cost in repairable systems design via genetic algorithms and discrete event simulation. Pesquisa Operacional, 29(1): 43-66.

[19] Parada Puig JE \& Basten RJI. 2015. Defining line replaceable units, European Journal of Operational Research, 247(1): 310-320.

[20] Pecht M, Dube M, Natishan M, Willians R, Banner J \& Knowles L. 2001. Evaluation of Built-in Test. IEEE Transactions on Aerospace and Electronic Systems, Vol. 37, No. 1, 266-271.

[21] Pessoa AA \& UChoA EB. 2011, Minicourse UFFLP: Integrando Programação Inteira Mista e Planilhas de Cálculo (Integrating Mixed Integer Programming and Spreadsheets). Simpósio Brasileiro de Pesquisa Operacional.

[22] Polanyi M. 2009. The tacit dimension. With a new foreword by Amartya Sen. Chicago, EUA: The University of Chicago Press.

[23] Previsich N. 2007. Built-in-test Equipment for Integrated Weapons Systems: Achieving Utility and User Acceptance, Master's Thesis of Science in Systems Engineering, Naval Postgraduate School, Monterey, CA, EUA.

[24] RAWAT M \& LAD BK. 2016a. Simultaneous selection of reliability design and level of repair for fleet systems. International Journal of System Assurance Engineering and Management, 7(2): 138-155.

[25] RAWAT M \& LAD BK. 2016b. An integrated approach for fleet level maintenance planning. International Journal of Performability Engineering, 11(3): 229-242.

[26] RAWAT M \& LAD BK. 2017. An integrated strategy for fleet maintenance planning. Journal of Quality in Maintenance Engineering, 23(4): 457-478.

[27] Rawat M, LAD BK \& Sharma A. 2020a. Simulation-based joint optimization of fleet system modularity and level of repair decisions considering different failure rates of components. Grey systems, 10(3), 377-390.

[28] Rawat M \& LAD BK. 2020b. Joint Optimization of Reliability Design and Level of Repair Analysis Considering Time Dependent Failure Rate of Fleet. System. Bulletin of Banking Statistics. International Journal of Performability Engineering. 16(6): 1-151.

[29] SARANGA H \& KUMAR UD. 2006. Optimization of aircraft maintenance/support infrastructure using genetic algorithms - level of repair analysis. Annals of Operations Research, 143(1): 91-106.

[30] SCHneider K \& CASSAdy CR. 2015, Evaluation and comparison of alternative fleetlevel selective Maintenance models. Reliability Engineering and System Safety, 134, $178-187$. 
[31] Shina T, Imaizumi J, Morito S, \& Xu C. 2017. Optimal Location Problem For The Installation Of Power Flow Controller. Pesquisa Operacional, 37(3): 509-524.

[32] United States Department of Defense. 1993 Military Standard Level of Repair Analysis (LORA). MIL-STD-1390D.

\section{How to cite}

Brick ES, Pessoa AA \& SACRAmento KT. 2021. Level of repair analysis including failure analysis and optimal location of maintenance facilities and resources. Pesquisa Operacional, 41: e238051. doi: 10.1590/0101-7438.2021.041.00238051. 


\section{APPENDIX A}

\section{Data used in test cases}

Here we describe artificial but reasonable test cases, designed to demonstrate formulation capabilities, assuming a 10-year maintenance policy.

Instances reasonableness's are based on realistic geographical and salary data in Brazil, and the tacit knowledge and previous experience in logistics studies and analysis in the Brazilian Navy and in a systems' engineering company.

It also stems from the unavailability of trustful and/or complete data sets that could be used for comparison with other studies. Additionally, it is worthwhile to mention that the main purpose of the tests was to assess and compare the effect and relevance of the various model characteristics included in the model, and not to compare it with other models, because no other one found in the literature contains all these characteristics. Finally, in order to reduce the influence of data on conclusions, various of the parameters were varied randomly in the experiments.

There are three systems (assets), having the indentation structures and possible fault indications depicted by Fig. 11, where numbers 1 to 4 represent imprecise BITE indications at LRUs belonging to set $T_{1}$, and the remaining numbers (5 to 20) represent fault modes, identified by pre-analysis precise indications, belonging to set $T_{2}$.
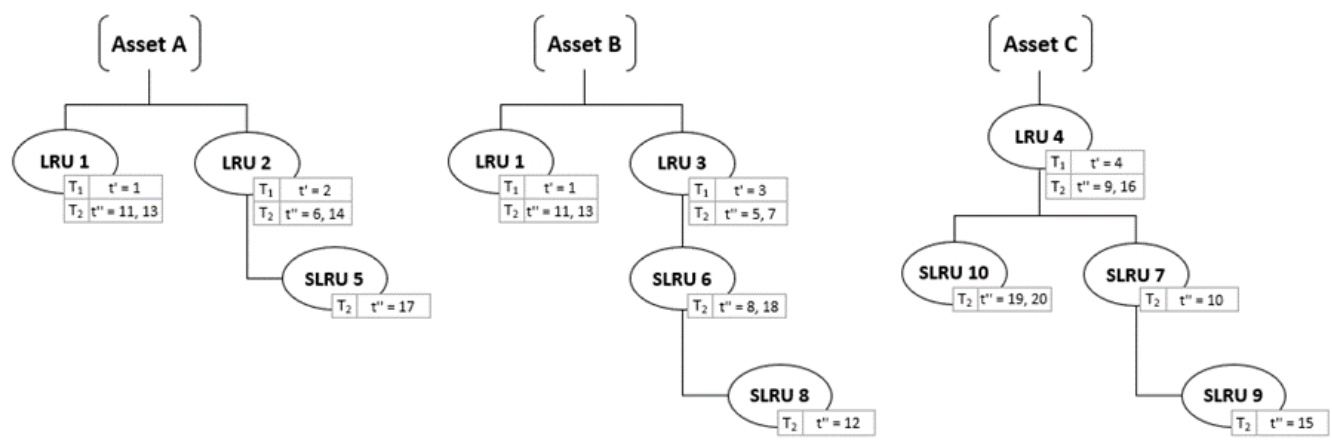

Figure 11 - Asset's structures used in the test cases.

The quantity of BITE indications of type $t^{\prime} \in T_{1}$ that occur at operation site $\mathrm{k}\left(d_{t^{\prime} k}\right)$ depends on life cycle operation time (OT), the quantity $(n)$ and the failure rate $\left(\lambda_{q}\right)$ of the LRU associated with $t^{\prime}$, according to the formula $n \times \lambda_{q} \times$ OT (expected number of failures in the period OT). OT is the same for all assets and equals 10 years. For each instance, the product $\lambda_{t}$ " $\times$ OT, for each fault $t " \in T_{2}$, was drawn from a uniform probability distribution in the range $[0.2 ; 20]$ and the failure rate $\left(\lambda_{q}\right)$ for a first indenture level LRU is the sum of the failure rates $\left(\lambda_{t}\right.$ ") of all faults contained in it, or in its descendants.

The operation sites $(k)$ are in the cities of Manaus (1), Belém (2), Fortaleza (3), Salvador (4), Cuiabá (5), Brasília (6), São Paulo (7), Rio de Janeiro (8), Curitiba (9) and Porto Alegre (10). 
These operation sites can also be maintenance sites $(J \cap K=K)$. An additional five potential maintenance sites exist in the cities of Porto Velho (11), Campo Grande (12), Recife (13), Belo Horizonte (14) and Florianopolis (15). Table 6 shows the number $n$ of installed assets for the three asset types of Fig. 4 at each of the 10 operation sites.

Table 6 - Number of assets per operation site.

\begin{tabular}{|c|c|c|c|}
\hline Operation site $(k)$ & Asset A & Asset B & Asset C \\
\hline 1 & 10 & 20 & 0 \\
\hline 2 & 10 & 40 & 0 \\
\hline 3 & 0 & 0 & 80 \\
\hline 4 & 0 & 0 & 50 \\
\hline 5 & 0 & 10 & 20 \\
\hline 6 & 50 & 0 & 0 \\
\hline 7 & 40 & 30 & 10 \\
\hline 8 & 0 & 0 & 40 \\
\hline 9 & 20 & 0 & 40 \\
\hline 10 & 40 & 40 & 20 \\
\hline
\end{tabular}

Resources' fixed installation costs depend on geographical location. Table 7 shows the basic costs of resources and Table 8 the cost multiplication factors according to the region. There are no limits for the resource quantities at each site. Intervals between brackets indicate that the data is drawn from a uniform distribution covering the given interval.

The "Facility Installation" resource is non-capacitated, and is required only for repair actions. The argument is that the simplest actions (analysis and disposal) require resources that can easily fit the existing operation facilities. On the other hand, resources for more complex repair actions require additional facilities and this greatly increases the cost of maintenance decentralization. The facilities' costs may depend on the quantity and diversity of resources they contain. As such, they are capacitated resources, with capacities measured by their physical dimensions. However, to simplify, the present model assumes that facilities are non-capacitated and that their implementation costs are fixed.

Resource usage varies with the fault indication and the action performed. Maintenance action costs depend on the node where they occur. For organic maintenance, Table 9 shows resource usage and maintenance cost, as a percent of the corresponding component cost .In the case of outsourcing, the maintenance cost values in the table are expressed as either a percent of the corresponding component cost, or as a multiplying factor applied to the organic cost.

Repair actions using equipment with high effectiveness and high-skilled workers have $100 \%$ effectiveness, but when using equipment with low effectiveness and low-skilled workers, only $75 \%$. In the latter case, $25 \%$ of the demand processed requires rework to repair or discard in a new try. The analysis and disposal actions are $100 \%$ effective. Table 10 shows resources needed per action. 
Table 7 - Resource cost and capacity data.

\begin{tabular}{|l|c|c|c|}
\hline \multirow{2}{*}{ Resource } & 10-year cost of ownership (\$) & \multicolumn{2}{|l|}{ 10 year capacity (operation hours) } \\
\cline { 3 - 4 } & $3,000,000$ & Normal & Extra \\
\hline $\begin{array}{l}\text { Equipment 1 with } \\
\text { low effectiveness }\end{array}$ & $8,000,000$ & 70,800 & 8,760 \\
\hline $\begin{array}{l}\text { Equipment 2 with } \\
\text { high effectiveness }\end{array}$ & {$[70,000 ; 1,200,000]$} & 70,800 & 8,760 \\
\hline $\begin{array}{l}\text { Pre-analysis and } \\
\text { replacement kit }\end{array}$ & $1,320,000$ & 19,200 & 8,760 \\
\hline $\begin{array}{l}\text { Worker 1 - high } \\
\text { skilled }\end{array}$ & 792,000 & 19,200 & 4,800 \\
\hline $\begin{array}{l}\text { Worker 2 - low } \\
\text { skilled }\end{array}$ & {$[10,000,000 ; 40,000,000]$} & 87,600 & 4,800 \\
\hline Facility Installation & & & \\
\hline
\end{tabular}

Table 8 - Resource installation cost multiplying factor.

\begin{tabular}{|c|c|c|c|}
\hline \multirow{2}{*}{ Site (j) } & \multicolumn{3}{|c|}{ Resource Cost Multiplying Factor } \\
\cline { 2 - 4 } & Equipment & Worker & Facility Installation \\
\hline 1,2 and 11 & 1.3 & 1.4 & 1.2 \\
\hline 3,4 and 13 & 1 & 1 & 1 \\
\hline 5,6 and 12 & 1.3 & 1.2 & 1.2 \\
\hline 7,8 and 14 & 1.2 & 1.1 & 1.2 \\
\hline 9,10 and 15 & 1.1 & 1 & 1.1 \\
\hline
\end{tabular}

Table 9 - Resource usages and maintenance costs.

\begin{tabular}{|c|l|c|c|l|}
\hline $\begin{array}{c}\text { Maintenance } \\
\text { action }\end{array}$ & Resource & $\begin{array}{c}\text { Resource } \\
\text { Usage (Hours) }\end{array}$ & $\begin{array}{c}\text { Organic Maintenance Costs } \\
(\% \text { of component cost) }\end{array}$ & $\begin{array}{l}\text { Outsourcing } \\
\text { Maintenance Costs }\end{array}$ \\
\hline Analysis & $\begin{array}{l}\text { Pre-analysis and } \\
\text { replacement kit }\end{array}$ & {$[2,7]$} & 0 & $\begin{array}{l}{[5,10] \text { (\% of component }} \\
\text { cost) }\end{array}$ \\
\hline Analysis & Worker & {$[4,8]$} & $\begin{array}{l}{[5,10] \text { (\% of component }} \\
\text { cost) }\end{array}$ \\
\hline Disposal & Worker & {$[1,4]$} & {$[120,150]$} & $1.2 \times$ to 1.3 organic cost \\
\hline Repair & $\begin{array}{l}\text { Equipment high } \\
\text { effectiveness }\end{array}$ & {$[3,8]$} & {$[14,20]$} & $3 \times$ to $4 \times$ organic cost \\
\hline Repair & $\begin{array}{l}\text { Worker high } \\
\text { effectiveness }\end{array}$ & {$[4,16]$} & {$[14,20]$} & $3 \times$ to $4 \times$ organic cost \\
\hline Repair & $\begin{array}{l}\text { Equipment low } \\
\text { effectiveness }\end{array}$ & {$[3,8]$} & {$[10,16]$} & $3 \times$ to $4 \times$ organic cost \\
\hline Repair & $\begin{array}{l}\text { Worker low } \\
\text { effectiveness }\end{array}$ & {$[4,16]$} & & $3 \times$ organic cost \\
\hline
\end{tabular}


When a failed maintenance attempt occurs, the faulty part usually is sent for service at a higher maintenance echelon. Since practical structures have up to four echelons, the number of maintenance attempts is limited to three in order to adhere to realistic situations.

Table 10 - Resource types required per maintenance action.

\begin{tabular}{|c|c|c|c|}
\hline Action & \multicolumn{3}{|c|}{ Necessary resources } \\
\hline Analysis & Worker 1 & Pre-analysis and replacement Kit & \\
\hline Disposal & Worker 2 & - & \\
\hline Repair high effectiveness & Worker 1 & Equipment 2 & Facility \\
\hline Repair low effectiveness & Worker 2 & Equipment 1 & Facility \\
\hline
\end{tabular}

Transportation costs are usually a function of distances, transportation mode and component value, volume and weight. Since we assume a single transportation mode, the cost of transporting the components between the locations is determined according to the component's attributes (volume, weight and value), and the distance between the origin and destination sites, according to the following equation.

$$
\text { tranportation cost }=\frac{\text { distance } \times(40 * \text { volume }+60 * \text { weight }+0,01 * \text { value })}{P}+100
$$

The parameter $P$ varies in the range [200;600]. 1/P is the distance factor reported in Table 5.

Table 11 presents the component data of the tested instances.

Table 11 - Component data.

\begin{tabular}{|c|c|c|c|}
\hline Component & Volume $\left(\mathrm{m}^{3}\right)$ & Weight $(\mathrm{kg})$ & Value $(\mathrm{R} \$)$ \\
\hline LRU 1 & 0.8 & 5.0 & 20,000 \\
\hline LRU 2 & 0.3 & 2.1 & 7,500 \\
\hline LRU 3 & 0.9 & 4.8 & 10,100 \\
\hline LRU 4 & 1.05 & 4.2 & 12,400 \\
\hline SLRU 5 & 0.1 & 0.5 & 2500 \\
\hline SLRU 6 & 0.4 & 0.8 & 4,800 \\
\hline SLRU 7 & 0.35 & 0.7 & 2,050 \\
\hline SLRU 8 & 0.1 & 0.3 & 1,150 \\
\hline SLRU 9 & 0.05 & 0.2 & 1,000 \\
\hline SLRU 10 & 0.5 & 2.5 & 8,200 \\
\hline
\end{tabular}

